\title{
Transcriptional and post-transcriptional regulation of the circadian clock of cyanobacteria and Neurospora
}

\author{
Michael Brunner ${ }^{1}$ and Tobias Schafmeier \\ Biochemie-Zentrum der Universität Heidelberg, 69120 Heidelberg, Germany
}

Circadian clocks are self-sustained oscillators modulating rhythmic transcription of large numbers of genes. Clock-controlled gene expression manifests in circadian rhythmicity of many physiological and behavioral functions. In eukaryotes, expression of core clock components is organized in a network of interconnected positive and negative feedback loops. This network is thought to constitute the pacemaker that generates circadian rhythmicity. The network of interconnected loops is embedded in a supra-net via a large number of interacting factors that affect expression and function of core clock components on transcriptional and post-transcriptional levels. In particular, phosphorylation and dephosphorylation of clock components are critical processes ensuring robust self-sustained circadian rhythmicity and entrainment of clocks to external cues. In cyanobacteria, three clock proteins have the capacity to generate a self-sustained circadian rhythm of autophosphorylation and dephosphorylation independent of transcription and translation. This phosphorylation rhythm regulates the function of these clock components, which then facilitate rhythmic gene transcription, including negative feedback on their own genes. In this article, we briefly present the mechanism of clock function in cyanobacteria. We then discuss in detail the contribution of transcriptional feedback and protein phosphorylation to various functional aspects of the circadian clock of $\mathrm{Neu}$ rospora crassa.

Circadian rhythms are found in numerous light-perceiving organisms including cyanobacteria, algae, fungi, plants, insects, and vertebrates. The rhythms are supported by cell-autonomous circadian clocks, which regulate expression of a large number of genes on the level of transcription (for review, see Roenneberg and Merrow 2003; Stanewsky 2003; Dunlap and Loros 2004; Gachon

[Keywords: Circadian clocks; circadian rhythms; feedback loops; phosphorylation]

${ }^{1}$ Corresponding author.

E-MAIL michael.brunner@urz.uni-heidelberg.de; FAX 49-6221-544769. Article and publication are at http://www.genesdev.org/cgi/doi/10.1101/ gad.1410406. et al. 2004; Iwasaki and Kondo 2004; Salome and McClung 2004; Hardin 2005). Most if not all genes in cyanobacteria and $\sim 10 \%$ of the genes in eukaryotes are transcribed under clock control, generating the potential to modulate thousands of biochemical and physiological parameters in rhythmic fashion (McDonald and Rosbash 2001; Akhtar et al. 2002; Duffield et al. 2002; Lewis et al. 2002; Correa et al. 2003; Nowrousian et al. 2003; Oishi et al. 2003; Nakahira et al. 2004). Circadian clocks are molecular oscillators that generate a robust self-sustained endogenous rhythm with a free-running period (period under constant conditions) of $\sim 24 \mathrm{~h}$. The endogenous time is synchronized to the external time, in nature the 24-h rhythm of earth rotation, by environmental cues (zeitgebers) such as light, temperature, and nutrition.

Transcriptional/translational feedback loops are hallmarks of circadian clocks in all organisms. In eukaryotes, expression of core clock components is organized in a complex network of interconnected positive and negative feedback loops (for review, see Dunlap and Loros 2004; Gachon et al. 2004; Hardin 2005). This network of gene expression is assumed to generate circadian rhythmicity. Elimination of key components of these interconnected loops disrupts many, if not all, rhythmic outputs, depending on the organism. Expression, subcellular localization, assembly, function, and turnover of clock components are crucial for circadian rhythmicity, and thus, the core clock is embedded in a supra-net of cellular machinery regulating various aspects of clock function. Protein phosphorylation and dephosphorylation are important regulatory mechanisms that are critical for self-sustained circadian rhythmicity and entrainment of clocks to external cues. It is unclear to what extent reversible phosphorylations are mechanistically instrumental for generation of rhythmicity in eukaryotic clocks.

Recent findings have shown that clock proteins in cyanobacteria generate a self-sustained circadian rhythm of autophosphorylation and dephosphorylation, which is independent of transcriptional/translational feedback (Nakajima et al. 2005; Tomita et al. 2005). This prompted us to discuss the contributions of transcriptional and posttranscriptional processes to the circadian system of Neurospora crassa. 


\section{The circadian clock of cyanobacteria}

Cyanobacteria are the only prokaryotes and thus the simplest candidates among the model organisms for circadian clocks. The oscillator of Synechococcus elongatus is constituted by the products of the kai genes: KaiA, $\mathrm{KaiB}$, and KaiC. The three genes are organized in a cluster, with kaiA being followed by the bicistronic kaiBC operon (Ishiura et al. 1998). The abundance level of kaiBC transcript oscillates with high amplitude in circadian manner, whereas the oscillation of kaiA RNA has a low amplitude (Ishiura et al. 1998). Disruption of any of the kai genes results in loss of circadian rhythmicity (Ishiura et al. 1998). Transcription of kaiBC depends on KaiA. Strains lacking active KaiA display reduced kaiBC promoter activity, and overexpression of KaiA causes an increase of kaiBC transcription, which results in arrhythmic gene expression. This indicates a direct or indirect role of KaiA as transcriptional activator. When $\mathrm{KaiC}$ is overexpressed under control of a heterologous promoter, transcription of kaiBC is reduced, suggesting that $\mathrm{KaiC}$ is a repressor of kaiBC. However, in the absence of $\mathrm{KaiC}$, transcription driven by the kaiBC promoter is not activated-that is, KaiA requires $\mathrm{KaiC}$ for transcriptional activation of kaiBC-suggesting that KaiC may be an activator, at least at some point during a circadian cycle (Iwasaki et al. 2002).

Promoter trap experiments suggest that many $(>800)$ if not all promoters of Synechococcus are regulated by KaiC (Nakahira et al. 2004). Furthermore, circadian rhythmicity was maintained, when the KaiBC promoter was replaced by an Escherichia coli-derived promoter (Xu et al. 2003; Nakahira et al. 2004). Thus, the target of KaiC is apparently neither a cis-acting element in the kaiBC promoter nor a transcription factor that specifically regulates this promoter.

Rather, KaiC targets the general transcription apparatus of Synechococcus and thereby regulates the entire transcriptome in circadian fashion. The transcriptionbased negative feedback loop is closed since the KaiB/C promoter is rhythmically affected by KaiC in the same manner as other output genes (Ishiura et al. 1998; Iwasaki et al. 2002; Nakahira et al. 2004).

KaiA is expressed at a constant level of $\sim 500$ molecules per cell; the abundance levels of $\mathrm{KaiB}$ and KaiC oscillate in the course of a circadian cycle around an average level of $\sim 10,000$ molecules per cell (Kitayama et al. 2003). KaiC consists of two structurally related ATP-binding domains (Iwasaki et al. 1999), and it belongs to the superfamily of bacterial DNA helicases/recombinases (Leipe et al. 2000). Like other members of this family, KaiC forms an ATP-dependent homo-hexameric complex (Mori et al. 2002). KaiC exhibits autokinase and autophosphatase activity, and it assembles with KaiA and $\mathrm{KaiB}$ into higher oligomeric complexes with distinct activities (Nishiwaki et al. 2000; Kageyama et al. 2003; Kitayama et al. 2003; Xu et al. 2003; Nakajima et al. 2005; Tomita et al. 2005). The phosphorylation status of KaiC oscillates in circadian fashion (Nishiwaki et al. 2004; Xu et al. 2004). Key phosphorylation sites have been identified that are essential for circadian rhythmicity (Xu et al. 2004).

Levels of KaiC protein peak around circadian time (CT) 16 (CT 0 corresponds to subjective dawn, CT 12 to subjective dusk), which is $\sim 4 \mathrm{~h}$ after levels of kaiBC RNA have reached their circadian peak (Xu et al. 2000). Hexameric KaiC by itself exhibits autophosphatase activity. KaiA stimulates the autokinase activity of KaiC, and KaiA-KaiC complexes are most abundant around CT 12-20. At CT 20, KaiB starts associating with KaiC and with the KaiA-KaiC complex and antagonizes the stimulatory effect of KaiA on autokinase activity of KaiC (Kitayama et al. 2003). This leads to auto-dephosphorylation of $\mathrm{KaiC}$ (CT 0-8) and to disassembly of large Kai complexes (Fig. 1; Kitayama et al. 2003).

Due to the structural similarity of KaiC to DNA helicases/recombinases, it was proposed that KaiC might recognize supercoiled chromosomal DNA (Mori and

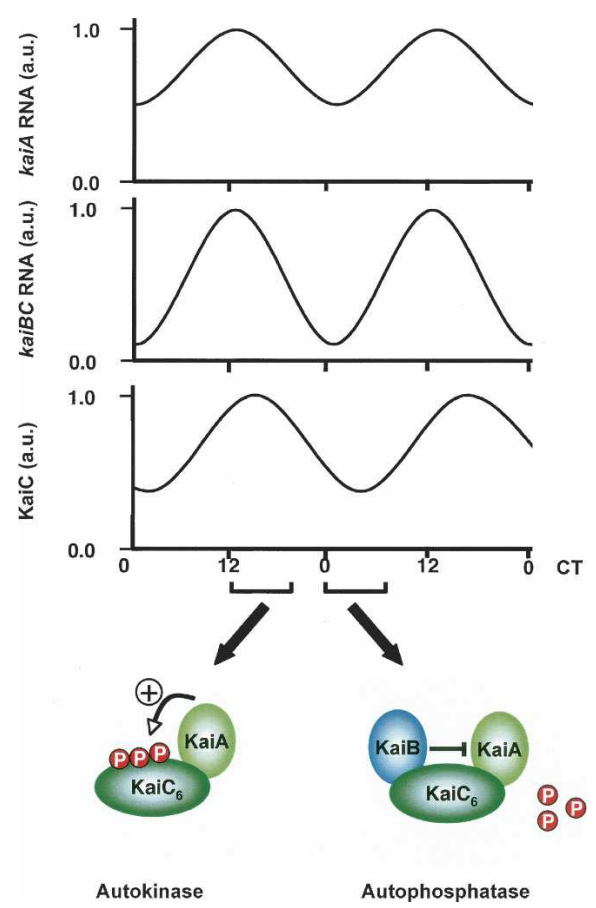

Figure 1. Oscillation of clock components and KaiC phosphorylation status in the cyanobacterial circadian clock. (Upper part) kaiA mRNA levels oscillate in LL (constant light) with approximately twofold amplitude with a maximum around CT 12. The kaiBC transcript shows a circadian rhythm, which is in phase with kaiA but displays higher amplitude. KaiC protein oscillation is time delayed in comparison to its mRNA and has an amplitude of $\sim 3$. (Lower part) Fluctuations of phosphorylation status of KaiC (dark-green oval) occur in LL as well as in DD (constant darkness), generating a feedback loop independent of transcription. Autophosphorylation activity of the hexameric KaiC complex is supported by KaiA (light-green oval) at the beginning of the subjective night (CT 12-20), resulting in predominantly hyperphosphorylated protein. Beginning in the subjective morning (CT 0-8), KaiB (blue-green oval) inhibits KaiA action and KaiC's autophosphatase activity dominates over its autokinase function, leading to dephosphorylation of KaiC. (Red circles) Phosphate groups. 
Johnson 2001). Despite the lack of an apparent DNAbinding motif, KaiC was reported to weakly bind to DNA (Mori et al. 2002). In the so-called chromosome oscillation model, it was suggested that KaiC interacts, dependent on its phosphorylation status, with DNA and promotes rhythmic fluctuations in chromosome compaction, leading to an overall circadian rhythm of gene expression (Iwasaki and Kondo 2004).

Recent results challenged the central role of a transcriptional feedback in generation of rhythmicity. Synechococcus is a photoautotrophic organism. In the absence of light, transcription comes rapidly to a halt. Yet, Synechococcus keeps the time in constant darkness, and KaiC is rhythmically phosphorylated over a time period of at least $56 \mathrm{~h}$ (Tomita et al. 2005). The phosphorylation rhythm persists even when transcription or translation is blocked by specific inhibitors (Tomita et al. 2005). This demonstrates that the circadian clock is running in constant darkness and that the transcription-based feedback loop is not required for time measurement under these conditions. Even more astonishing was the observation that KaiC phosphorylation and dephosphorylation cycles can be reconstituted independent of transcription and translation when KaiA, KaiB, and KaiC are incubated in vitro at physiological ratios in the presence of ATP (Nakajima et al. 2005). These exciting findings suggest that self-sustained circadian oscillation is generated by rhythmic phosphorylation of KaiC rather than by a transcriptional/translational feedback loop, which appears to be an output of the phosphorylationbased pacemaker (Nakajima et al. 2005; Tomita et al. 2005).

Yet, kaiBC is rhythmically transcribed in vivo, and it has to be elucidated how the transcription/translationbased oscillation in protein abundance and the oscillating phosphorylation status of KaiC contribute to the clock mechanism. In a growing Synechococcus culture, the concentration of Kai proteins is diluted by turnover, cell growth, and division. Accordingly, the pool of Kai proteins must be replenished by de novo synthesis. Newly synthesized protein is unmodified-that is, not phosphorylated. Since unphosphorylated and phosphorylated forms of KaiC assemble into different complexes with distinct function, constitutive de novo synthesis of KaiC may compromise robust circadian rhythmicity of KaiC phosphorylation. De novo synthesis may only be tolerable at times of day when unphosphorylated $\mathrm{KaiC}$ is expected to be the prevailing species. Transcription of kaiBC sets in after KaiC autophosphatase activity has reached its maximum. Subsequent expression of KaiC may ensure that autophosphorylation of newly synthesized KaiC is in phase with the phosphorylation rhythm of previously synthesized KaiC. Thus, in a growing Synechococcus culture, rhythmic expression of kaiBC might be essential for rhythmicity although the KaiC phosphorylation/dephosphorylation cycle is the circadian pacemaker generating the rhythm independent of transcriptional feedback.

In the filamentous fungus $N$. crassa, components of the circadian clock also undergo cycles of phosphoryla- tion. However, according to our current understanding, the rhythm is generated by interconnected transcriptional/translational feedback loops, and phosphorylation events modulating clock protein activity are thought to depend on rhythmic expression of clock proteins. In the following section, we discuss the role of transcriptional and post-transcriptional steps of the Neurospora clock with respect to pacemaker function.

\section{The circadian clock of $N$. crassa}

Frequency (FRQ) and the GATA-type transcription factors White Collar-1 (WC-1) and White Collar-2 (WC-2) are core elements of interconnected transcriptional/ translational feedback loops of the circadian clock of $N$. crassa (for review, see Dunlap and Loros 2004). WC-1 and WC-2 assemble forming the White Collar complex (WCC), which activates $f_{r} q$ transcription. FRQ protein then inhibits the activity of WCC and thereby feeds back on its own synthesis and regulates other genes controlled by WCC (Aronson et al. 1994). Due to the feedback regulation, $f_{r q}$ RNA and FRQ protein display high-amplitude circadian abundance rhythms. In an interconnected positive loop, FRQ supports accumulation of high levels of WCC, primarily on a post-transcriptional or post-translational level (Lee et al. 2000; Cheng et al. 2001b; Schafmeier et al. 2006). These apparently conflicting functions of FRQ are coordinated in temporal and spatial fashion: Negative feedback is carried out by low levels of nuclear FRQ, while support of WCC levels requires progressive accumulation of high levels of FRQ in the cytosol (Schafmeier et al. 2006).

Levels of $w c-1$ and $w c-2$ RNA are not rhythmic. WC-1 displays an abundance rhythm almost antiphasic to frq (Lee et al. 2000). WC-2 is expressed in high but constant amounts throughout the circadian period. WC-1, the limiting component of the WCC, accumulates only when assembled with its partner WC-2 (Cheng et al. 2002). FRQ, WC-1, and WC-2 are phosphorylated proteins (Garceau et al. 1997; Talora et al. 1999; Schwerdtfeger and Linden 2000; He et al. 2005a; Schafmeier et al. 2005). The average levels of FRQ and WC-1 are similar, while WC-2 is expressed in about a fivefold higher amount (Denault et al. 2001; Schafmeier et al. 2005). The WCC is highly concentrated in the nucleus, while excess WC-2 is found in the nucleus and cytosol (Schwerdtfeger and Linden 2000; Schafmeier et al. 2005). WCC binds to clock- and light-responsive elements in the frq promoter and activates $f r q$ transcription (Froehlich et al. 2002, 2003). Levels of $f r q$ RNA begin to rise in the late (subjective) night (around CT 20) and peak shortly after dawn (CT 0-4) (Crosthwaite et al. 1997; Garceau et al. 1997; Luo et al. 1998; Dunlap 1999). At this time, low levels of newly synthesized, hypophosphorylated FRQ are detectable. The newly synthesized FRQ is active as a repressor of its own transcription (Merrow et al. 1997; Schafmeier et al. 2006). Accordingly, frq RNA levels are decreasing in the further course of the morning, until synthesis of frq RNA is maximally repressed in the late afternoon (Fig. 2, upper part; Crosthwaite et al. 1997; Garceau et al. 


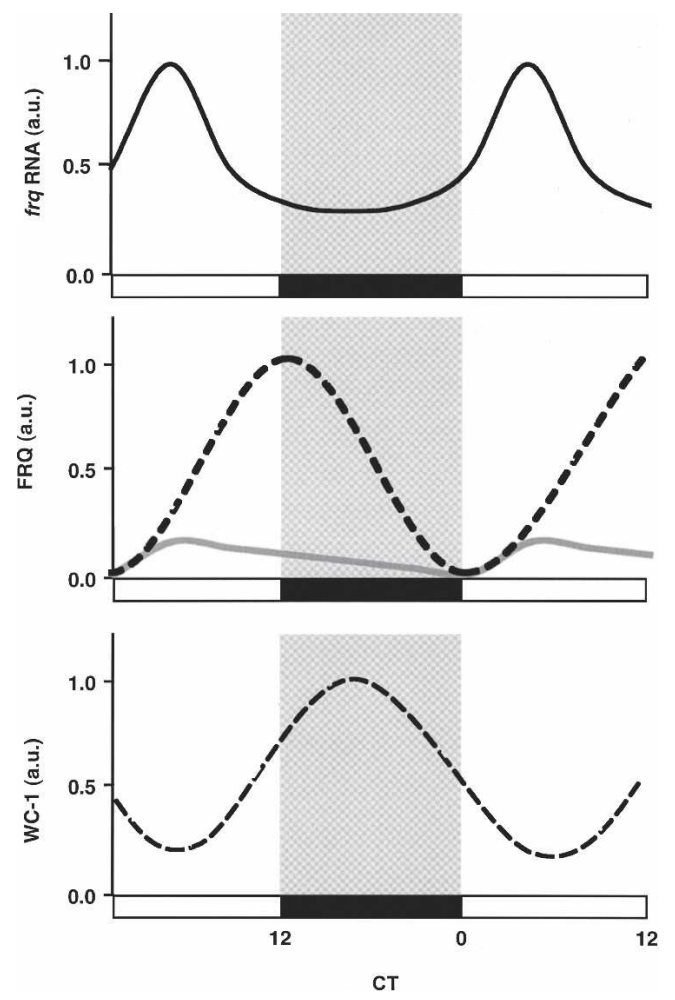

Figure 2. Schematic representation of the circadian abundance rhythms of frq RNA, FRQ, and WC-1 under free-running conditions. The amplitudes are $\sim 3$ for frq RNA (upper panel, black solid line) and $\sim 5$ for FRQ (middle panel). FRQ protein levels are shown as cytosolic (black dashed line) and nuclear levels (gray solid line). (Lower panel) WC-1 protein levels oscillate almost in antiphase to frq RNA (black dashed line). Maxima have been set to 1.0. Shaded areas and black bars indicate the subjective night.

1997; Görl et al. 2001). The previously synthesized FRQ becomes progressively phosphorylated at multiple sites. In the course of the night (CT 12-20), hyperphosphorylated FRQ is degraded, and FRQ levels decrease. Yet, frq RNA synthesis remains repressed until CT 20, when only low levels of hyperphosphorylated FRQ are present. Interestingly, the levels of hyperphosphorylated FRQ present toward the end of the night (CT 20), when negative feedback is about to be relieved, are comparable to the levels of hypophosphorylated FRQ present in the morning (CT 4), when newly synthesized FRQ is active as a repressor (Luo et al. 1998).

The molecular mechanisms underlying the time-ofday specific differences in apparent repressor capacity of FRQ are not known. Repressor capacity could be determined directly by the phosphorylation status of FRQ. Alternatively, since specifically nuclear FRQ is active in negative feedback, the time-of-day-dependent differences in FRQ function may reflect the differences in its subcellular distribution; that is, a low concentration of nuclear FRQ before dawn versus a considerably higher concentration of nuclear FRQ in the course of the morning (Luo et al. 1998; Schafmeier et al. 2006).

\section{Physical properties of FRQ}

FRQ does not contain evolutionarily conserved domains with known functions. It is organized in a high-molecular-weight assembly of heterogeneous size. FRQ contains a predicted coiled-coil segment that is localized in the $\mathrm{N}$-terminal portion of the protein. The coiled coil is required for the formation of FRQ dimers, and it is essential for clock function (Cheng et al. 2001a). The FRQ complex contains casein kinase 1a (CK-1a) (Görl et al. 2001) and FRH, a DEAD-box-containing RNA helicase. While all FRQ is in a stable complex with FRH, the binding between FRQ and CK-1a appears to be substoichiometric or unstable (Cheng et al. 2005). FRQ is mostly found in the cytosol (see below), while FRH, which seems to be expressed in excess over FRQ, is equally abundant in the cytosol and in nuclei (Cheng et al. 2005). The Saccharomyces cerevisiae homolog of FRH, Doblp/ Mtr4p, is a cofactor of the exosome complex, which regulates metabolism of various RNA species including mRNA (Mitchell and Tollervey 2000; Torchet et al. 2002; Hilleren and Parker 2003). FRH is essential for the viability of Neurospora, indicating that is has an important function independent of the circadian clock. Although this FRQ-independent essential role of FRQ is not known, the FRH/FRQ complex is required for negative feedback and thus for clock function. FRH was also found to interact with WC-1 and WC-2 in a FRQ-independent manner (Cheng et al. 2005).

FRQ contains a nuclear localization signal, which is necessary for its function as a repressor (Luo et al. 1998), and it is localized in the cytosol and in nuclei (Luo et al. 1998; Schafmeier et al. 2005). Newly synthesized FRQ is about equally concentrated in both compartments (Luo et al. 1998; Schafmeier et al. 2006). Yet, since nuclei make up only $\sim 10 \%$ of the volume of the cytosol, $>90 \%$ of FRQ is located in the cytosol (Schafmeier et al. 2005, 2006). Nuclear levels of FRQ reach a maximum shortly after the onset of FRQ synthesis (CT 4), while the cytosolic levels of FRQ increase further and reach their maximum in the subjective afternoon (Luo et al. 1998). Eight hours to $12 \mathrm{~h}$ after FRQ induction, the vast majority of FRQ is located in the cytosol, and the concentration of FRQ is higher in the cytosol than in nuclei (Luo et al. 1998; Cheng et al. 2005; Schafmeier et al. 2005, 2006). Accumulation of FRQ is accompanied by progressive hyperphosphorylation, but it is not known whether the subcellular distribution of FRQ is regulated by phosphorylation. It is also not known whether only a specific fraction of FRQ is competent to enter the nucleus or whether the majority of FRQ is retained in the cytosol. Alternatively, FRQ may dynamically shuttle between both compartments, and the kinetics of nuclear entry versus export could be regulated in circadian fashion.

In the course of a circadian period, FRQ is phosphorylated at multiple sites and hyperphosphorylated FRQ is degraded (Fig. 3, upper part; Liu et al. 2000). FRQ interacts with FWD-1, a component of an SCF (Skp1-Cul1F-box protein)-type ubiquitin ligase, which directs protein substrates to degradation by the proteasome (He et 


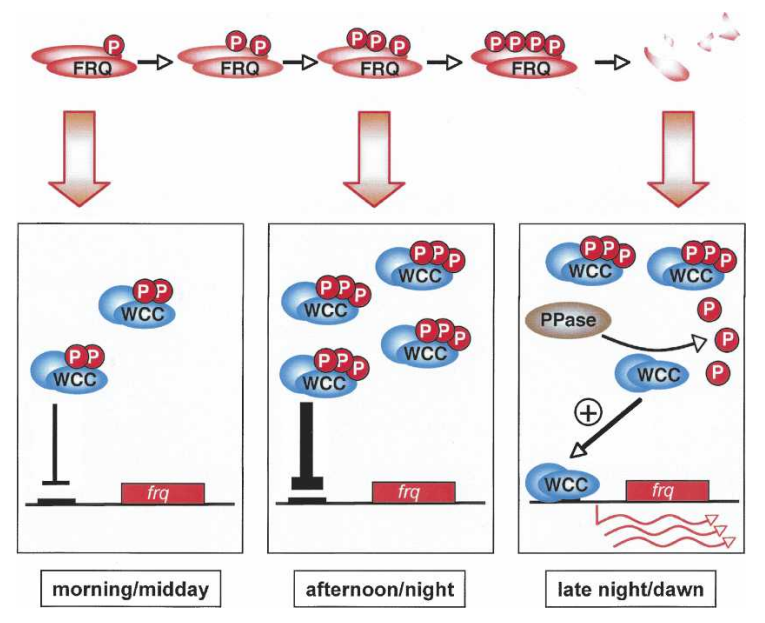

Figure 3. Phosphorylation of FRQ and WCC regulates distinct aspects of the circadian clock of $N$. crassa. (Upper part) FRQ (red ovals) is progressively phosphorylated in the course of a circadian period, resulting in its maturation from a nuclear repressor toward a cytoplasmic activator of WCC (blue ovals). Hyperphosphorylated FRQ is degraded at the end of each circadian cycle. (Red circles) Phosphate groups. (Lower part) Phosphorylation status, activity, and abundance of the WCC are controlled by FRQ. (Morning/midday) Low amounts of WCC are present in the nucleus. WCC becomes progressively phosphorylated, mediated by newly synthesized, hypophosphorylated FRQ. Hyperphosphorylated WCC binds only weakly to the clock-box (black bar) of the frq promoter (red rectangle), and $f r q$ transcription is not activated. (Afternoon/night) High levels of hyperphosphorylated FRQ have accumulated in the cytosol, supporting expression of WCC to replenish the pool. Nuclear FRQ supports phosphorylation of WCC, keeping it in inactive form. frq is maximally repressed. (Late night/dawn) As hyperphosphorylated FRQ becomes degraded, PP2A-dependent dephosphorylation of WCC dominates over FRQ-dependent phosphorylation, leading to activation of $f r q$ transcription (red arrows).

al. 2003; He and Liu 2005a). Phosphorylation of FRQ could be a direct signal for recruitment of degradation machinery, or it could regulate particular maturation steps of FRQ and thereby affect the kinetics of turnover in indirect fashion. The stability of the $\mathrm{SCF}^{\mathrm{FWD}-1} \mathrm{com}$ plex is controlled by the COP9 signalosome. COP9 mediates deneddylation of the cullin subunit, which is required for recycling of the $\mathrm{SCF}^{\mathrm{FWD}-1}$ complex. In a COP9-deficient strain, FRQ degradation is retarded and circadian rhythmicity is severely compromised (He et al. 2005b).

Several putative phosphorylation sites of FRQ were proposed on the basis of site-directed mutagenesis, deletion analysis, and in vitro phosphorylation of FRQ fusion proteins and FRQ-derived peptides. Furthermore, protein kinases and phosphatases have been identified, which phosphorylate and dephosphorylate FRQ in vitro and affect FRQ phosphorylation status and clock function in vivo (Liu et al. 2000; Görl et al. 2001; Yang et al. 2001, 2002, 2003, 2004; Schafmeier et al. 2006). When putative phosphorylation sites are mutated or when the function of a particular kinase or phosphatase is compromised, the overall kinetics of FRQ turnover and/or clock function is affected.

Exchange of a single serine residue (S513 to arginine or isoleucine) dramatically slows down FRQ turnover and results in lengthening of the circadian period ( $>31 \mathrm{~h}$ ) (Liu et al. 2000). Exchange of S513 to aspartate restores the degradation kinetics of FRQ but results in a loss of overt rhythmicity. A kinase phosphorylating S513 is not known. Calcium/calmodulin-dependent kinase (CAMK1) phosphorylates in vitro a GST fusion protein with the central portion of FRQ (residues 425-683) (Yang et al. 2001). A CAMK-1-deficient strain shows, however, little effect on clock function and FRQ phosphorylation in vivo, presumably because the structurally related CAMK-2 is redundant in function. The same GST-FRQ fusion protein is phosphorylated in vitro by casein kinase II (CKII) (Yang et al. 2002, 2003). CKII is a heterotetrameric enzyme consisting of two catalytic $\alpha$ subunits encoded by the cka gene and two different regulatory $\beta$ subunits encoded by $c k b 1$ and $c k b 2$. A strain defective in the CKII catalytic subunit $\left(c k a^{R I P}\right)$ and a strain with a deletion of $c k b 1$ are severely affected in cell growth and development. The $c k a^{R I P}$ strain expresses elevated levels of $f r q$ RNA with no apparent circadian abundance rhythm (Yang et al. 2002). These data suggest that phosphorylation of FRQ by CKII is important for repression of frq. In Drosophila, CKII-dependent phosphorylation of the circadian clock protein PERIOD (PER) enhances its repressor activity (Nawathean and Rosbash 2004). Neurospora CKII may modulate the repressor capacity of FRQ in similar fashion.

The $c k b 1$ deletion strain also expresses elevated levels of $f r q$ RNA. It displays a low-amplitude, long-period rhythm of frq RNA and FRQ protein abundance (Yang et al. 2003). In both strains, FRQ is hypophosphorylated and turned over with reduced kinetics. CKII phosphorylates serine and threonine side chains $(\mathrm{S} / \mathrm{T})$ that are located three residues $\mathrm{N}$-terminal of an acidic $(\mathrm{D} / \mathrm{E})$ or previously phosphorylated ( $\mathrm{Sp} / \mathrm{Tp}$ ) residue. FRQ contains 29 CKII consensus sites of the type (S/T)XX(D/E). Mutation of either four or six of these consensus sites resulted in a detectable loss of hyperphosphorylated FRQ species, suggesting that these sites are phosphorylated by CKII in vivo (Yang et al. 2003). The mutant strains display longperiod circadian rhythms (27.1-30.7 h) of frq RNA and FRQ abundance.

FRQ contains two PEST-like sequences (Merrow and Dunlap 1994). The acronym PEST refers to an enrichment of proline $(\mathrm{P})$, aspartate and glutamate $(\mathrm{E})$, serine $(\mathrm{S})$, and threonine (T) residues (Rogers et al. 1986). In many cases, PEST sequences are targets for phosphorylation and implicated in the regulation of protein turnover (Rechsteiner and Rogers 1996; Marchal et al. 1998; Roth and Davis 2000). Both PEST-1 (amino acid residues 544-560) and PEST-2 (residues 843-893) of FRQ appear to be phosphorylated in vivo (Görl et al. 2001; Schafmeier et al. 2006). Deletion of PEST-1 (FRQ $\Delta$ P-1) results in stabilization of FRQ. A strain expressing FRQ $\Delta$ P-1 displays a long-period circadian abundance rhythm (28 h) of frq $\Delta P-1$ RNA and FRQ $\Delta \mathrm{P}-1$ protein but 
has lost the rhythm of conidiation (formation of asexual spores). Thus, PEST-1 regulates FRQ turnover and affects clock function, and its deletion dissociates molecular and overt rhythmicity. PEST-1 is phosphorylated in vitro by casein kinase 1a (CK-1a) (Görl et al. 2001). Neurospora CK-1a is the homolog of Drosophila DOUBLETIME and mammalian $\mathrm{CKI} \varepsilon / \delta$, which are both essential for circadian rhythmicity in flies and mammals (Kloss et al. 1998, 2001; Price et al. 1998; Lowrey et al. 2000; Vielhaber et al. 2000; Lee et al. 2001).

PEST-2 is phosphorylated in vitro by CK-1a and by CK-1b, the product of the second ckI gene of Neurospora. Interestingly, CK-1b does not phosphorylate PEST-1 in vitro (Görl et al. 2001) and is not found in a stable complex with FRQ in vivo (T. Heise and M. Brunner, unpubl.). This suggests that CK-1a and CK-1b have distinct functions. CK-1b is crucial for Neurospora growth and development but has no apparent function in the circadian clock (Yang et al. 2003). However, it cannot be ruled out that PEST-2 is phosphorylated in redundant fashion by CK-1a and CK-1b in vivo.

CK-1a phosphorylates the serine (S) residues 885 and 887 of PEST 2 (Schafmeier et al. 2006). Phosphorylation of these sites neither affects FRQ turnover nor negative feedback on its own transcription nor subcellular distribution. Rather, deletion of PEST-2 or mutation of S885 and S887 affects accumulation of WC-1, the limiting subunit of WCC. When S885 and S887 were changed to asparagine to prevent phosphorylation, expression levels of WC-1 were low and the corresponding strain had lost overt and molecular circadian rhythmicity (Schafmeier et al. 2006). In contrast, when the residues were changed to aspartate to mimic phosphorylation, expression levels of WC-1 were restored. The corresponding strain was rhythmic, but its phase of conidiation was advanced by 3 h compared with a control strain (Schafmeier et al. 2006). This suggests that phosphorylation of PEST-2 is required for the FRQ-mediated support of WC-1 expression and that the kinetics of phosphorylation is critical for the phase of conidiation.

Protein phosphatases (PP) are also important regulators of FRQ and clock function in Neurospora. PP1 and PP2A are two major serine/threonine phosphatases in eukaryotic cells. Several regulatory subunits determine specificity and subcellular localization of these phosphatases (Virshup 2000; Janssens and Goris 2001; Cohen 2002).

FRQ is dephosphorylated by PP1 and PP2A in vitro, and both phosphatases regulate FRQ and the circadian clock in vivo in a specific manner (Yang et al. 2004). It is not known whether these phosphatases are expressed in rhythmic fashion. PP1 positively regulates FRQ stability. A Neurospora strain harboring a partially functional allele of the catalytic subunit of PP1 $\left(p p p-1^{R I P}\right)$ displays a high-amplitude rhythm of frq RNA and FRQ abundance. The free-running period of the $p p p-1^{R I P}$ strain is shortened, and its phase of conidiation is advanced, suggesting that a lack of PP1-dependent dephosphorylation accelerates the circadian clock. A strain lacking functional RGB-1 $\left(r g b-1^{R I P}\right)$, a regulatory subunit of PP2A, is se- verely compromised in cell growth and displays irregular conidiation patterns with $>24$-h rhythms. Although FRQ stability is not altered, overall levels of frq RNA and FRQ protein are reduced in the $r g b-1^{\text {RIP }}$ strain (Yang et al. 2004). The low expression of frq RNA reflects a function of PP2A in activating WCC, the transcriptional activator of frq (Schafmeier et al. 2005). However, an additional direct function of PP2A in FRQ dephosphorylation cannot be excluded.

In summary, the kinetics and status of FRQ phosphorylation are dependent on several protein kinases (CAMK-1, CK-1a, and CKII) and protein phosphatases (PP1 and PP2A), and furthermore, hitherto unidentified protein kinases and phosphatases may additionally be involved in these processes. The slow progression of FRQ phosphorylation over an extended time course of several hours may reflect the balanced activity of multiple kinases and phosphatases, leading to a steady net phosphorylation reaction that proceeds with considerably slow kinetics. These enzymes thereby regulate the kinetics of FRQ turnover and function on the time scale of a circadian period. It is not known whether the rates of FRQ phosphorylation and dephosphorylation underlie circadian modulation and whether such a rhythm would be independent of rhythmic expression transcription/ translation. In particular, it is not known whether hyperphosphorylated FRQ can be rescued from degradation under specific conditions and become functionally reactivated by dephosphorylation, in a similar manner as KaiC in cyanobacteria.

\section{The WCC}

WC-1 and WC-2 are GATA-type transcription factors that form the heteromeric WCC (Talora et al. 1999; Cheng et al. 2002). WC-1 does not accumulate to high levels in the absence of its partner WC-2, which is expressed in excess over WC-1 (Denault et al. 2001). WCC is highly concentrated in nuclei, while WC-2 is found in the cytosol and nuclei (Schwerdtfeger and Linden 2000). The WCC regulates expression of frq (Crosthwaite et al. 1997) and several clock-controlled and light-inducible genes. It is not known whether WC-2 that is not assembled with WC-1 has additional functions in either nuclei or cytosol. WC-1 contains three PAS domains, PAS-A, PAS-B, and PAS-C, followed by a stretch of basic residues that could function as an NLS and by a GATAtype zinc finger (Zn-finger) domain (Ballario et al. 1996, 1998). In addition, WC-1 contains glutamine-rich stretches at its $\mathrm{N}$ and $\mathrm{C}$ termini, which were proposed to act as transcriptional activation domains, but direct data supporting such function are not available. WC-1 serves also a role as blue-light photoreceptor. PAS-A is a specialized, so-called LOV (light-oxygen-voltage) domain, which is required for light responses of Neurospora (Ballario et al. 1998). WC-2 contains a single PAS domain followed by a GATA-type Zn-finger (Linden and Macino 1997; Ballario et al. 1998). It contains basic regions flanking the Zn-finger that may serve as NLS, although these sequences deviate from the canonical NLS consensus. 
WC-1 and WC-2 can enter the nucleus independent of each other (Schwerdtfeger and Linden 2000; Cheng et al. 2002), but it is not known whether WCC assembly is mechanistically confined to a specific subcellular compartment. Four DNA-binding sites for the WCC have been identified by EMSA or ChIP; two sites in the fr $q$ promoter, one in the albino-3, and one in the vivid promoter. Derived from this very limited number of sites, WCC may bind to tandem GATN repeats in the context of GATN-C-X (3-14) $^{-C-G A T N}$, with $\mathrm{N}$ being variable but the same nucleotide in both motifs (He et al. 2005a).

\section{Mechanism of negative feedback}

WCC activates frq transcription by binding to two elements in the frq promoter, the proximal light-responsive element (pLRE) and the distal LRE or clock box (Froehlich et al. 2002, 2003), and FRQ feeds back on the synthesis of its own RNA by inhibiting WCC. In accordance, frq RNA levels begin to decline when levels of nuclear FRQ are highest. However, the phase of the abundance rhythm of $f r q$ RNA is similar to the phase of the nuclear FRQ abundance (Luo et al. 1998). In particular, levels of frq RNA and levels of nuclear FRQ are decreasing in parallel during the subjective night, indicating that repression of $f_{r} q$ transcription becomes stronger, although levels of nuclear FRQ are decreasing. Furthermore, levels of WCC are highest in the subjective night when frq RNA and nuclear FRQ levels are close to their circadian minimum (Fig. 2; Lee et al. 2000; Denault et al. 2001; Görl et al. 2001; Schafmeier et al. 2005, 2006). Therefore, neither the abundance of nuclear FRQ nor the molar ratio of FRQ versus WCC correlates with repression of $f r q$ transcription. In addition, the molar levels of nuclear FRQ are at all times lower than the levels of WCC (Schafmeier et al. 2005), and the vast majority of the WCC is not stably associated with FRQ (Denault et al. 2001; He et al. 2005a; Schafmeier et al. 2005). Thus, FRQ is unlikely to neutralize WCC directly via formation of a 1:1 complex. A small fraction of WCC appears to be associated with FRQ and vice versa (Denault et al. 2001; He et al. 2002; Cheng et al. 2005). This could reflect a transient or unstable interaction of these clock components, but the functional significance of the interaction remains to be established.

We have recently shown that FRQ regulates the activity of WCC by modulating the phosphorylation status of both subunits, WC-1 and WC-2, rather than by direct complex formation (Schafmeier et al. 2005). WCC in its hyperphosphorylated form displays a lower affinity for the clock box and is less active in supporting frq transcription than hypophosphorylated WCC (Fig. 3). WC-2 is heterogeneously phosphorylated at up to six or more sites. Its phosphorylation status oscillates in circadian fashion and correlates with frq transcription. Hyperphosphorylated WC-2 species are most abundant around dusk and in the first half of the subjective night and least abundant around dawn. WC-1 is also phosphorylated in an FRQ-dependent manner, but it is not clear for technical reasons whether its phosphorylation status oscil- lates in circadian fashion. Activation of WCC is dependent on RGB-1, a regulatory subunit of PP2A, and accompanied by dephosphorylation of WC-1 and WC-2 (Fig. 3; Schafmeier et al. 2005). Thus, the rhythmic activity of WCC is controlled by phosphorylation and dephosphorylation, and the equilibrium established by WCC kinase and phosphatase activity seems to be modulated by FRQ in circadian fashion. Interestingly, neither WC-1 nor WC-2 is fully dephosphorylated when frq RNA levels are at their circadian peak, suggesting that the pool of WCC never becomes fully activated during a circadian cycle. Similarly, WCC is heterogeneously phosphorylated when $f_{r q}$ RNA levels are at their circadian trough, suggesting that WCC may never become totally inactivated. In fact, $f_{r q}$ transcription is never fully repressed, such that low levels of FRQ are synthesized even when frq RNA levels are at circadian troughs. Full activation of WCC can be artificially achieved when FRQ expression via a controllable promoter is tightly repressed or when FRQ synthesis is inhibited by cycloheximide (Schafmeier et al. 2005). Such artificial activation of WCC is accompanied by extensive dephosphorylation of WCC and by a tremendous increase in frq transcription.

Thus, in constant conditions, FRQ-mediated inactivation of WCC sets in already before the pool of WCC is fully activated, and a pool of WCC that is only partially active drives circadian oscillation of $f_{r} q$ RNA abundance. FRQ appears to modulate the WCC kinase/phosphatase equilibrium only in a subtle manner such that the progression of net phosphorylation and dephosphorylation is considerably slow, and activation and deactivation of the WCC occur on a circadian time scale.

Maintaining WCC in mostly inactive form throughout the entire circadian cycle and recruiting active WCC primarily from this pool rather than by de novo synthesis could contribute to robustness of the oscillation. De novo synthesis of WC-1 and WC- 2 would serve the purpose of replenishing the WCC pool rather than being mechanistically instrumental in generation of rhythmicity.

\section{Positive feedback loop}

The negative feedback loop is connected with a positive loop (or positive loops) by which FRQ supports the accumulation of high levels of WCC (Lee et al. 2000; Cheng et al. 2001b). This support of WCC accumulation is partially due to a transcriptional feedback since WCC is a transcriptional repressor of $w c-2$ and FRQ is an activator of $w c-2$ transcription (Cheng et al. 2001b, 2003a). The underlying mechanism is not known, but it could be similar to the regulation of feedback loops in the circadian clocks in mammals and flies: In mice, CLOCK/ BMAL1 activates transcription of the orphan nuclear receptors Rev-erb $\alpha$ and Ror $\alpha$, encoding a repressor and a transcriptional activator, respectively, of Bmal1 (Preitner et al. 2002; Ueda et al. 2002; Sato et al. 2004; Akashi and Takumi 2005). In Drosophila, dCLOCK/CYCLE ac- 
tivate Vrille and $P d p 1$, repressor and activator, respectively, of dClock (Cyran et al. 2003; Glossop et al. 2003).

Thus, WCC could activate expression of a putative transcriptional repressor of $w c-2$. Since FRQ is an inhibitor of WCC, it would indirectly activate $w c-2$ transcription via repression of the putative repressor, similar to PERIOD proteins (PERs) in the positive feedback loops in mammals and flies (Bae et al. 1998; Shearman et al. 2000; Preitner et al. 2002; Cyran et al. 2003). FRQ also affects transcription of $w c-1$, which is to some extent dependent on WCC (Linden and Macino 1997; Káldi et al. 2006). Yet, neither gene is transcribed in rhythmic fashion, and feedback of FRQ on $w c-1$ and $w c-2$ transcription is neither necessary nor sufficient for the support of WCC accumulation (Lee et al. 2000; Cheng et al. 2001b; Dragovic et al. 2002; Káldi et al. 2006; Schafmeier et al. 2006). In particular, levels of WCC are dependent on FRQ even when $w c-1$ and $w c-2$ are efficiently transcribed under control of a heterologous promoter (Cheng et al. 2001b; Schafmeier et al. 2006). Induced transcription of $w c-2$ results in overexpression of WC-2 protein but does not facilitate accumulation of WCC in the absence of FRQ, demonstrating that transcription/translation of WC-2 is not limiting for WCC formation (Schafmeier et al. 2006). Induced transcription of $w c-1$ does not result in a significant increase of WC-1 in frq-deficient strains (Schafmeier et al. 2006), but it is difficult to distinguish whether FRQ facilitates translation of $w c-1$ RNA or formation of the WCC on a post-translational level. As mentioned above, FRQ is associated with the putative RNA helicase FRH, and the FRQ/FRH complex is located predominantly in the cytosol. It is intriguing to speculate that the FRQ/FRH complex may regulate WC-1 expression on the level of translation. However, if FRQ regulates $w c-1$ translation, the signals for translational control must lie within the central or C-terminal portion of the WC-1 ORF, since induced expression of an $\mathrm{N}$-terminally truncated version of WC-1 was FRQ dependent (Schafmeier et al. 2006).

Support of WCC accumulation requires progressive accumulation of FRQ in the cytosol and post-translational modification of FRQ. Phosphorylation of serine residues within the PEST-2 region of FRQ appears to be crucial for the ability of FRQ to support WCC levels. Phosphorylation of PEST-2 does not affect the capacity of FRQ to feedback-inhibit its own transcription. Thus, the transcriptional function of FRQ in the negative loop and its post-transcriptional or post-translational function in the positive loop are independent. This suggests that FRQ acts in distinct subcellular compartments and via apparently distinct mechanisms in the negative and positive limbs of the circadian feedback loops. Distinct populations of FRQ, differing by phosphorylation status, mediate the nuclear and cytosolic functions, and progressive phosphorylation of FRQ seems to trigger its maturation from a nuclear repressor toward a cytoplasmic activator (Fig. 3; Schafmeier et al. 2006). During a circadian cycle, newly synthesized, hypophosphorylated FRQ acts as a repressor promoting phosphorylation of WCC in the nucleus. Later in the cycle, hypo- and hyperphosphory- lated forms of FRQ have accumulated in cytosol and nuclei and FRQ exerts both functions; cytoplasmic FRQ supports accumulation of high levels of WCC, and the newly assembled WCC is then efficiently inactivated by nuclear FRQ. Thus, at this stage in the cycle, FRQ supports accumulation of high levels of its inactive transcription factor such that $f r q$ transcription remains repressed. Later in the cycle, FRQ is predominantly hyperphosphorylated and on the pathway to degradation. The PP2A-dependent dephosphorylation of WCC then dominates kinetically over FRQ-dependent phosphorylation, and the accumulated inactive WCC becomes progressively activated, leading to the relief of negative feedback and to the start of a new circadian period (Fig. 3; Schafmeier et al. 2005).

The molecular mechanism by which cytosolic FRQ controls WCC levels is not known. However, it is tempting to speculate that cytosolic FRQ might act by a similar mechanism as FRQ in the nucleus; that is, via regulation of the phosphorylation status of WCC subunits. Recently, five serine residues C-terminal of the $\mathrm{Zn}$-finger domain of WC-1 were identified, which are phosphorylated under constant conditions. When these serines are changed to alanine residues, the level of WCC is reduced. However, the levels of frq RNA and protein levels in the mutant appear to be comparable to wild type or even slightly elevated, suggesting that these phosphorylations negatively regulate WC-1 activity $(\mathrm{He}$ et al. 2005a). It remains to be investigated whether phosphorylation of these sites is dependent on FRQ.

Under constant conditions, WCC was found in association with PKC (protein kinase C) (Franchi et al. 2005). Expression of constitutive active and dominant-negative mutant versions of PKC results in reduced and elevated levels of WCC, respectively, suggesting that PKC is a negative regulator of WCC levels. (Franchi et al. 2005; Loros 2005). Whether FRQ affects WCC levels via modulating PKC activity was not investigated.

\section{Signal transduction of light}

All known light responses of Neurospora are mediated by blue light, and they presumably all require the $w c-1$ and $w c-2$ genes encoding the subunits of the WCC (Ballario et al. 1996; Linden and Macino 1997; Linden et al. 1997; He et al. 2002; Lee et al. 2003). The WCC mediates light responses via activation of light-induced genes. The light activation is direct with immediate light-inducible genes (Class IL, induction begins after $\leq 5 \mathrm{~min}$ ) (Lewis et al. 2002) but may be indirect with late-response genes (Classes IIL and IIIL) (for review, see Liu et al. 2003). The albino genes (al-1, al-2, al-3) (Schmidthauser et al. 1990, 1994; Carattoli et al. 1994), which are responsible for light-induced synthesis of carotenoids, as well as frq are the best studied immediate early light-inducible genes in Neurospora, whereas the clock-controlled genes ccg-1 and $c c g-2$ are late genes with an expression peak 1-2 h after a light pulse. Microarray analysis on the basis of $\sim 1400$ genes suggested that $\sim 3 \%$ of the genes are light inducible (Linden et al. 1997; Lewis et al. 2002). This 
may be an underestimation since genes expressed at low levels are not detected on the arrays.

Immediate light responses are gated by the circadian clock such that identical light signals result in higher induction in the subjective morning (Heintzen et al. 2001; Merrow et al. 2001). Interestingly, the circadian response to light corresponds to the circadian phosphorylation and activity status of the WCC (Schafmeier et al. 2005), suggesting that only a fraction of the WCC might be susceptible to light activation. Following the initial increase, the levels of light-induced RNA decrease despite the presence of continuous light and reach a considerably low steady state after $2 \mathrm{~h}$ in constant light. This so-called light adaptation process is facilitated by the blue-light receptor, VIVID (VVD), which also affects the circadian gating of light responses via an unknown mechanism (Heintzen et al. 2001).

WC-1 contains a LOV domain, similar to the LOV domain of phototropins, the flavin-dependent blue light photoreceptors in plants (Briggs and Christie 2002). In comparison with the FMN (flavin-adenine mononucleotide)-binding plant phototropins, the LOV domain of WC-1 is associated with FAD (He et al. 2002; Cheng et al. 2003b).

The mechanism of light induction of genes via the WCC is partially understood. Light exposure of Neurospora transiently induces binding of the WCC to LREs (light-responsive elements) in promoters of immediate light-induced genes and enhances the capacity of WCC to activate transcription (He and Liu 2005b). The kinetics of light-induced LRE binding of WCC is rapid, peaking $\sim 5$ min after light exposure. In comparison, the kinetics of WC-1 hyperphosphorylation is considerably slower and peaks 15-30 min after light exposure. In particular, little hyperphosphorylated WC-1 is present after 5 min, when the affinity of WCC for the LRE is highest (He and Liu 2005b). In vitro, the electrophoretic mobility of complexes of the WCC and LRE-derived oligonucleotides is reduced after light exposure and binding of WCC to the LRE is increased, suggesting that the composition and/or conformation of WCC-LRE complexes is different in light and in dark (Froehlich et al. 2002). Lightinduced formation of WCC-LRE complexes in vitro does not require phosphorylation of WC-1. On the contrary, treatment of hyperphosphorylated WC-1 with phosphatase increases binding of WCC to an LRE. Therefore, light received by the LOV domain of WC-1 may induce a conformational change allowing formation of light-specific WCC-LRE complexes. At the same time, light exposure renders WCC susceptible to phosphorylation by hitherto unidentified kinases. Phosphorylation then leads, with a kinetic delay, to inactivation of WCC by reducing its affinity for LREs (He and Liu 2005b).

The pathway of reactivation of photoactivated WC-1 is not entirely clear. Hyperphosphorylated WC-1 disappears rapidly after photoactivation, partially by degradation and in part by dephosphorylation. Photoactivated WC-1 is less stable in continuous light, and a considerable fraction seems to be degraded (Talora et al. 1999; Lee et al. 2000). In contrast, WC-1 is stable in the dark (Lee et al. 2000; Schafmeier et al. 2005), and photoactivated WC-1 seems to be rapidly dephosphorylated within $2 \mathrm{~h}$ after a light-to-dark transfer (He et al. 2005a). Following light exposure and transfer to dark, the dephosphorylated WC-1 is not able to be activated by light for several hours, suggesting that the photocycle of WC-1 is very slow in comparison with the rapid photocycle of plant phototropins (He et al. 2005a). In constant light, newly synthesized WC-1 replenishing the pool of WCC may be rapidly activated and then become deactivated by degradation and phosphorylation, respectively, resulting in elevated steady-state activity of WCC in LL /constant light). Since the fraction of newly synthesized WC-1 is low, there might be considerable competition among promoters for the small pool of transiently active WCC. This might be the reason for the different expression levels in LL of immediate light-induced genes such as fr $q, v v d$, and al-3. In summary, hyperphosphorylation of WC-1 after a light pulse correlates with induction of light-induced genes, but the reported findings suggest that the WCC is inactivated by phosphorylation ( $\mathrm{He}$ and Liu 2005b).

VVD is a small protein that acts as a repressor of light responses by desensitization of the WCC photoreceptor system (Heintzen et al. 2001; Schwerdtfeger and Linden 2001; Shrode et al. 2001). It is a blue light photoreceptor (Heintzen et al. 2001; Cheng et al. 2003b) containing a flavin-binding LOV domain (Schwerdtfeger and Linden 2003), but its mode of action is not known. $v v d$ is a typical immediate light-induced gene that is controlled by the WCC, and it is not expressed in constant darkness (Heintzen et al. 2001; Schwerdtfeger and Linden 2001; Shrode et al. 2001; He et al. 2005a). Following light exposure, transcription of $v v d$ is rapidly induced, reaching a peak after $\sim 15 \mathrm{~min}$. Subsequently, RNA levels decrease and reach a low but detectable steady state. VVD levels peak $\sim 30 \mathrm{~min}$ after light exposure. In constant light, VVD is constitutively expressed at intermediate levels (Elvin et al. 2005). VVD mediates the rapid light adaptation of WCC-dependent transcription of immediate light-induced genes, including its own transcription. In $v v d$-deficient strains, immediate light-induced genes are transcribed for a prolonged period, and the light-induced hyperphosphorylation of WC-1 persists for several hours (Heintzen et al. 2001; Schwerdtfeger and Linden 2001). VVD, at least the vast majority, is localized in the cytosol (Schwerdtfeger and Linden 2003), while WCC is concentrated in nuclei. The molecular mechanism by which VVD affects the activity and phosphorylation status of WCC in the nucleus is not known.

frq transcription is strongly induced by light (for review, see Dunlap and Loros 2004). As a consequence, frq RNA abundance directly reflects the light environment in LD cycles, suggesting that $f r q$ transcription is lightdriven or masked by light (Tan et al. 2004). Yet, since the phase of conidiation is systematically entrained in photoperiod and $\mathrm{T}$ cycles, the circadian clock is running under such conditions. VVD is an important element contributing to light-entrainment of the circadian clock (Heintzen et al. 2001; Elvin et al. 2005). When Neuro- 
spora is transferred from light to dark, $v v d$ seems to be rhythmically expressed with strongly dampening amplitude such that no $v v d$ RNA is detected after $>40 \mathrm{~h}$ in darkness (Heintzen et al. 2001). VVD is not required for free-running rhythmicity of the clock in darkness. Rather, it seems to allow the clock to run through the light period (Elvin et al. 2005), and it affects the phase of conidiation after a light-to-dark transfer (Heintzen et al. 2001). VVD mutes the light response at dawn by inhibiting WCC, and it affects frq RNA levels at dusk, potentially via turnover (Elvin et al. 2005). Together, both effects contribute entrainment by light.

\section{Temperature sensing}

Two adjacent promoters control transcription of the frq gene. Corresponding frq RNA species are synthesized with long 5'-untranslated regions (UTRs), which are spliced in complex fashion (Liu et al. 1997; Colot et al. 2005; Diernfellner et al. 2005). In addition, an antisense transcript covering the FRQ ORF is synthesized in low abundance (Kramer et al. 2003). A single ORF encodes a large (1) and a small (s) isoform of FRQ, consisting of 989 and 890 amino acid residues, respectively, due to translation initiation at methionine codons in positions 1 and 100 of the ORF (Garceau et al. 1997).

l-FRQ versus s-FRQ are expressed in temperature-dependent fashion. The expression level of 1-FRQ rises with increasing ambient temperature, while s-FRQ is expressed in essentially temperature-independent manner. The ratio and abundance of l-FRQ versus s-FRQ are crucial for high-amplitude self-sustained rhythmicity and for temperature compensation of the circadian clock (Garceau et al. 1997; Liu et al. 1997). Resetting of the clock by temperature is mediated via the levels of FRQ (Liu et al. 1998). FRQ levels correlate with the amplitude of clock output, and a temperature-dependent threshold level of FRQ is required to maintain overt rhythmicity (Liu et al. 1997; Cheng et al. 2001b; Diernfellner et al. 2005).

Thermosensitive splicing and translation regulate the ratio and abundance of FRQ isoforms, respectively. The ratio of 1 -FRQ versus s-FRQ is regulated by thermosensitive splicing of intron 6 (I-6) of frq RNA, which results in excision of the translation initiation site of 1-FRQ /Colot et al. 2005; Diernfellner et al. 2005). The splice sites of I- 6 deviate from consensus, and the thermosensitivity of splicing is due to inefficient recognition of these nonconsensus splice sites by the splicing machinery at elevated temperature (Diernfellner et al. 2005). Accordingly, I-6 is spliced more efficiently at low temperature, which results in accumulation of fr $q$ RNA species that encode only s-FRQ.

The abundance of FRQ (1-FRQ + s-FRQ) is regulated by a temperature-dependent translational control mechanism that is independent of but interconnected with the thermosensitive splicing of frq RNA (Diernfellner et al. 2005). The 5'-UTR of frq RNA contains several upstream ORFs (uORFs) (Liu et al. 1997; Diernfellner et al. 2005). The AUG codons of these uORFs are in nonconsensus context for translation initiation. As a consequence, the uORFs are more efficiently translated at low temperature, leading to a reduction of translation initiation at the downstream ORFs encoding l-FRQ and s-FRQ (Diernfellner et al. 2005). Thus, thermosensitive trapping of scanning ribosomes at the uORFs allows adjustment of FRQ levels according to ambient temperature. Both mechanisms together regulate ratio and abundance of l-FRQ versus s-FRQ in temperature-dependent fashion. The functional difference between l-FRQ and s-FRQ is not known yet.

\section{Conclusions}

In summary, interconnected positive and negative transcriptional/translational feedback loops are strictly required for free-running circadian rhythmicity of the FRQ-based oscillator in Neurospora. FRQ undergoes a circadian cycle of rhythmic synthesis and phosphorylation, but there is no evidence suggesting that hyperphosphorylated FRQ is reactivated by dephosphorylation. Rather, hyperphosphorylated FRQ is unstable and committed to degradation. Cycles of FRQ synthesis and degradation appear to be instrumental for the generation of robust circadian rhythmicity. Accordingly, rhythmic expression of $f r q$, driven by a transcriptional/translational feedback loop, seems to be a crucial part of the rhythmgenerating mechanism. The WCC is the transcriptional activator of $f r q$, and it supposedly drives, directly and indirectly, rhythmic expression of all genes controlled by the FRQ-based oscillator. In comparison to FRQ, the WCC is stable and undergoes cycles of inactivation and activation regulated by cyclic phosphorylation and dephosphorylation, respectively. Rhythmic synthesis of WCC subunits is not required for self-sustained circadian oscillation, and de novo synthesis appears to serve the purpose of replenishing the WCC pool that becomes reduced by turnover and by cell growth. It is not known, whether WCC kinases and phosphatases could generate a self-sustained phosphorylation cycle of WCC, similar to the self-sustained phosphorylation cycle of cyanobacterial KaiC. However, since FRQ modulates the kinase/ phosphatase equilibrium, generation of a high amplitude WCC phosphorylation cycle requires rhythmic activity of FRQ, which seems to be dependent on transcriptional/ translational feedback.

It should be pointed out that all genes that are strictly required for overt circadian rhythmicity are either core clock genes ( $f r q, w c-1$, and $w c-2)$ or genes affecting their expression and function. Yet, partial or residual functions of the frq-based oscillator, in particular temperature-entrainable rhythmicity of conidiation, can also be observed in frq-deficient mutants, suggesting that additional oscillatory systems substitute for $f r q$ under specific conditions (Merrow et al. 1999; Correa et al. 2003; Pregueiro et al. 2005; Roenneberg et al. 2005). Components of such frq-less oscillators (FLOs) are not yet identified. Whether FLOs depend on rhythmically phosphorylated WCC is not known. A daily rhythm in nitrate synthase activity was reported to be independent of FRQ 
and of WCC (Christensen et al. 2004), but molecular components driving this oscillation are unknown.

Circadian rhythmicity in mice and Drosophila is dependent on complex networks of interconnected negative and positive feedback loops, which are organized in similar manner as in Neurospora. In mice, mPeriod's (mPer's) and Chryptochrome's (Cry's) feedback inhibit their own synthesis by inactivating their transcriptional activator CLOCK/BMAL-1 (CLK/BMAL1) (for review, see Gachon et al. 2004). In Drosophila, Per and Timless (Tim) inhibit their activator dCLOCK/CYCLE (dCLK/CYC) (for review, see Stanewsky 2003; Hardin 2005). mPER/CRY in mice and PER/TIM in flies are hyperphosphorylated in the course of a circadian period and then degraded. The phosphorylation status of PER is dependent on PP2A (Sathyanarayanan et al. 2004), but there is no evidence for reactivation by dephosphorylation of any of these components in a new circadian cycle. The transcriptional activators CLK/BMAL1 and CLK/ CYC undergo daily rhythms in abundance, but the phase of these rhythms does not correlate with the expression rhythm of many target genes, suggesting a more complex regulation (Lee et al. 1998, 2001; Kim et al. 2002; Gachon et al. 2004). CLK/BMAL1 induce reversible acetylation as well as cyclic di- and trimethylation of histones (Etchegaray et al. 2003; Ripperger and Schibler 2006). The kinetics of chromatin remodeling rather than CLK/ BMAL1 abundance may thus determine the phase of target gene transcription. CLK in mice and dCLK in Drosophila are phosphorylated in circadian manner (Lee et al. 1998, 2001; Kim et al. 2002). Little is known about the functional role of phosphorylation of these components in rhythmic chromatin remodeling and circadian activation of transcription.

\section{Acknowledgments}

This work was supported by grants from Deutsche Forschungsgemeinschaft (BR1375-1 and SFB683).

\section{References}

Akashi, M. and Takumi, T. 2005. The orphan nuclear receptor $\mathrm{ROR} \alpha$ regulates circadian transcription of the mammalian core-clock Bmal1. Nat. Struct. Mol. Biol. 12: 441-448.

Akhtar, R.A., Reddy, A.B., Maywood, E.S., Clayton, J.D., King, V.M., Smith, A.G., Gant, T.W., Hastings, M.H., and Kyriacou, C.P. 2002. Circadian cycling of the mouse liver transcriptome, as revealed by cDNA microarray, is driven by the suprachiasmatic nucleus. Curr. Biol. 12: 540-550.

Aronson, B.D., Johnson, K.A., Loros, J.J., and Dunlap, J.C. 1994. Negative feedback defining a circadian clock: Autoregulation of the clock gene frequency. Science 263: 1578-1584.

Bae, K., Lee, C., Sidote, D., Chuang, K.Y., and Edery, I. 1998. Circadian regulation of a Drosophila homolog of the mammalian Clock gene: PER and TIM function as positive regulators. Mol. Cell. Biol. 18: 6142-6151.

Ballario, P., Vittorioso, P., Magrelli, A., Talora, C., Cabibbo, A., and Macino, G. 1996. WHITE COLLAR-1, a central regulator of blue light responses in Neurospora, is a zinc finger protein. $E M B O$ J. 15: 1650-1657.
Ballario, P., Talora, C., Galli, D., Linden, H., and Macino, G. 1998. Roles in dimerization and blue light photoresponse of the PAS and LOV domain of Neurospora crassa white collar proteins. Mol. Microbiol. 29: 719-729.

Briggs, W.R. and Christie, J.M. 2002. Phototropins 1 and 2: Versatile plant blue-light receptors. Trends Plant Sci. 7: 204210.

Carattoli, A., Cogoni, C., Morelli, G., and Macino, G. 1994. Molecular characterization of upstream regulatory sequences controlling the photoinduced expression of the albino-3 gene of Neurospora crassa. Mol. Microbiol. 13: 787795.

Cheng, P., Yang, Y., Heintzen, C., and Liu, Y. 2001a. Coiled-coil domain-mediated FRQ-FRQ interaction is essential for its circadian clock function in Neurospora. EMBO J. 20: 101108.

Cheng, P., Yang, Y., and Liu, Y. 2001b. Interlocked feedback loops contribute to the robustness of the Neurospora circadian clock. Proc. Natl. Acad. Sci. 98: 7408-7413.

Cheng, P., Yang, Y., Gardner, K.H., and Liu, Y. 2002. PAS domain-mediated WC-1/WC-2 interaction is essential for maintaining the steady-state level of WC-1 and the function of both proteins in circadian clock and light responses of Neurospora. Mol. Cell. Biol. 22: 517-524.

Cheng, P., Yang, Y., Wang, L., He, Q., and Liu, Y. 2003a. WHITE COLLAR-1, a multifunctional Neurospora protein involved in the circadian feedback loops, light sensing, and transcription repression of wc-2. J. Biol. Chem. 278: 3801-3808.

Cheng, P., He, Q., Yang, Y., Wang, L., and Liu, Y. 2003b. Functional conservation of light, oxygen, or voltage domains in light sensing. Proc. Nat1. Acad. Sci. 100: 5938-5943.

Cheng, P., He, Q., He, Q., Wang, L., and Liu, Y. 2005. Regulation of the Neurospora circadian clock by an RNA helicase. Genes \& Dev. 19: 234-241.

Christensen, M.K., Falkeid, G., Loros, J.J., Dunlap, J.C., Lillo, C., and Ruoff, P. 2004. A frq-independent nitrate reductase rhythm in Neurospora crassa. J. Biol. Rhythms 19: 280-286.

Cohen, P.T. 2002. Protein phosphatase 1-Targeted in many directions. J. Cell Sci. 115: 241-256.

Colot, H.V., Loros, J.J., and Dunlap, J. 2005. Temperature-modulated alternative splicing and promoter use in the circadian clock gene frequency. Mol. Biol. Cell 16: 5563-5571.

Correa, A., Lewis, Z.A., Greene, A.V., March, I.J., Gomer, R.H., and Bell-Pedersen, D. 2003. Multiple oscillators regulate circadian gene expression in Neurospora. Proc. Natl. Acad. Sci. 100: 13597-13602.

Crosthwaite, S.K., Dunlap, J.C., and Loros, J.J. 1997. Neurospora $w c-1$ and $w c-2$ : Transcription, photoresponses, and the origin of circadian rhythmicity. Science 276: 763-769.

Cyran, S.A., Buchsbaum, A.M., Reddy, K.L., Glossop, N.R., Hardin, P.E., Young, M.W., Storti, R.V., and Blau, J. 2003. vrille, Pdp1 and dClock form a second loop in the Drosophila circadian clock. Cell 112: 329-341.

Denault, D.L., Loros, J.J., and Dunlap, J.C. 2001. WC-2 mediates WC-1-FRQ interaction within the PAS protein-linked circadian feedback loop of Neurospora. EMBO J. 20: 109-117.

Diernfellner, A.C.R., Schafmeier, T., Merrow, M.W., and Brunner, M. 2005. Molecular mechanism of temperature-sensing by the circadian clock of Neurospora crassa. Genes \& Dev. 19: $1968-1973$.

Dragovic, Z., Tan, Y., Gorl, M., Roenneberg, T., and Merrow, M. 2002. Light reception and circadian behavior in 'blind' and 'clock-less' mutants of Neurospora crassa. EMBO J. 21: 3643-3651.

Duffield, G.E., Best, J.D., Meurers, B.H., Bittner, A., Loros, J.J., and Dunlap, J.C. 2002. Circadian programs of transcriptional 
activation, signaling, and protein turnover revealed by microarray analysis of mammalian cells. Curr. Biol. 12: 551557.

Dunlap, J.C. 1999. Molecular bases for circadian clocks. Cell 96: 271-290.

Dunlap, J.C. and Loros, J.J. 2004. The Neurospora circadian system. J. Biol. Rhythms 19: 414-424.

Elvin, M., Loros, J.J., Dunlap, J.C., and Heintzen, C. 2005. The PAS/LOV protein VIVID supports a rapidly dampened daytime oscillator that facilitates entrainment of the Neurospora circadian clock. Genes \& Dev. 19: 2593-2605.

Etchegaray, J.P., Lee, C., Wade, P.A., and Reppert, S.M. 2003. Rhythmic histone acetylation underlies transcription in the mammalian circadian clock. Nature 421: 177-182.

Franchi, L., Fulci, V., and Macino, G. 2005. Protein kinase C modulates light responses in Neurospora by regulating the blue light photoreceptor WC-1. Mol. Microbiol. 56: 334-345.

Froehlich, A.C., Liu, Y., Loros, J.J., and Dunlap, J.C. 2002. White Collar-1, a circadian blue light photoreceptor, binding to the frequency promoter. Science 297: 815-819.

Froehlich, A.C., Loros, J.J., and Dunlap, J.C. 2003. Rhythmic binding of a WHITE COLLAR-containing complex to the frequency promoter is inhibited by FREQUENCY. Proc. Natl. Acad. Sci. 100: 5914-5919.

Gachon, F., Nagoshi, E., Brown, S.A., Ripperger, J., and Schibler, U. 2004. The mammalian circadian timing system: From gene expression to physiology. Chromosoma 113: 103-112.

Garceau, N.Y., Liu, Y., Loros, J.J., and Dunlap, J. 1997. Alternative initiation of translation and time-specific phosphorylation yield multiple forms of the essential clock protein FREQUENCY. Cell 89: 469-476.

Glossop, N.R., Houl, J.H., Zheng, H., Ng, F.S., Dudek, S.M., and Hardin, P.E. 2003. VRILLE feeds back to control circadian transcription of Clock in the Drosophila circadian oscillator. Neuron 37: 249-261.

Görl, M., Merrow, M., Huttner, B., Johnson, J., Roenneberg, T., and Brunner, M. 2001. A PEST-like element in FREQUENCY determines the length of the circadian period in Neurospora crassa. EMBO J. 20: 7074-7084.

Hardin, P.E. 2005. The circadian timekeeping system of Drosophila. Curr. Biol. 15: R714-R722.

He, Q. and Liu, Y. 2005a. Degradation of the Neurospora circadian clock protein FREQUENCY through the ubiquitin-proteasome pathway. Biochem. Soc. Trans. 33: 953-956.

- 2005b. Molecular mechanism of light responses in Neurospora: From light-induced transcription to photoadaptation. Genes \& Dev. 19: 2888-2899.

He, Q., Cheng, P., Yang, Y., Wang, L., Gardner, K.H., and Liu, Y. 2002. WHITE COLLAR-1, a DNA binding transcription factor and a light sensor. Science 297: 840-843.

He, Q., Cheng, P., Yang, Y., He, Q., Yu, H., and Liu, Y. 2003. FWD1-mediated degradation of FREQUENCY in Neurospora establishes a conserved mechanism for circadian clock regulation. EMBO J. 22: 4421-4430.

He, Q., Shu, H., Cheng, P., Chen, S., Wang, L., and Liu, Y. 2005a. Light-independent phosphorylation of WHITE COLLAR-1 regulates its function in the Neurospora circadian negative feedback loop. J. Biol. Chem. 280: 17526-17532.

He, Q., Cheng, P., He, Q., and Liu, Y. 2005b. The COP9 signalosome regulates the Neurospora circadian clock by controlling the stability of the SCFFWD-1 complex. Genes \& Dev. 19: $1518-1531$.

Heintzen, C., Loros, J.J., and Dunlap, J.C. 2001. The PAS protein VIVID defines a clock-associated feedback loop that represses light input, modulates gating, and regulates clock resetting. Cell 104: 453-464.
Hilleren, P.J. and Parker, R. 2003. Cytoplasmic degradation of splice-defective pre-mRNAs and intermediates. Mol. Cell 12: $1453-1465$.

Ishiura, M., Kutsuna, S., Aoki, S., Iwasaki, H., Andersson, C.R., Tanabe, A., Golden, S.S., Johnson, C.H., and Kondo, T. 1998. Expression of a gene cluster kaiABC as a circadian feedback process in cyanobacteria. Science 281: 1519-1523.

Iwasaki, H. and Kondo, T. 2004. Circadian timing mechanism in the prokaryotic clock system of cyanobacteria. J. Biol. Rhythms 19: 436-444.

Iwasaki, H., Taniguchi, Y., Ishiura, M., and Kondo, T. 1999. Physical interactions among circadian clock proteins, KaiA, KaiB and KaiC, in cyanobacteria. EMBO J. 18: 1137-1145.

Iwasaki, H., Nishiwaki, T., Kitayama, Y., Nakajima, M., and Kondo, T. 2002. KaiA stimulated KaiC phosphorylation in circadian timing loops in cyanobacteria. Proc. Natl. Acad. Sci. 99: 15788-15793.

Janssens, V. and Goris, J. 2001. Protein phosphatase 2A: A highly regulated family of serine/threonine phosphatases implicated in cell growth and signalling. Biochem. J. 353: 417-439.

Kageyama, H., Kondo, T., and Iwasaki, H. 2003. Circadian formation of clock protein complexes by KaiA, KaiB, KaiC, and SasA in cyanobacteria. J. Biol. Chem. 278: 2388-2395.

Káldi, K., Herreros-Gonzales, B., and Brunner, M. 2006. Transcriptional regulation of the Neurospora circadian clock gene wc-1 affects the phase of circadian output. EMBO Rep. 7: 199-204.

Kim, E.Y., Bae, K., Ng, F.S., Glossop, N.R.J., Hardin, P.E., and Edery, I. 2002. Drosophila CLOCK protein is under posttranscriptional control and influences light-induced activity. Neuron 34: 69-81.

Kitayama, Y., Iwasaki, H., Nishiwaki, T., and Kondo, T. 2003. KaiB functions as an attenuator of KaiC phosphorylation in the cyanobacterial circadian clock system. EMBO J. 22: 2127-2134.

Kloss, B., Price, J.L., Saez, L., Blau, J., Rothenfluh, A., Wesley, C.S., and Young, M.W. 1998. The Drosophila clock gene double-time encodes a protein closely related to human casein kinase I $\varepsilon$. Cell 94: 97-107.

Kloss, B., Rothenfluh, A., Young, M.W., and Saez, L. 2001. Phosphorylation of PERIOD is influenced by cycling physical associations of doubletime, period, and timeless in the Drosophila clock. Neuron 30: 699-706.

Kramer, C., Dunlap, J.C., Loros, J.J., and Crosthwaite, S.K. 2003. Role for antisense RNA in regulating circadian clock function in Neurospora crassa. Nature 421: 948-952.

Lee, C., Bae, K., and Edery, I. 1998. The Drosophila CLOCK protein undergoes daily rhythms in abundance, phosphorylation, and interactions with the PER-TIM complex. Neuron 21: 857-867.

Lee, K., Loros, J.J., and Dunlap, J.C. 2000. Interconnected feedback loops in the Neurospora circadian system. Science 289: 107-110.

Lee, C., Etchegaray, J., Cagampang, F.R.A., Loudon, A.S.I., and Reppert, S.M. 2001. Posttranslational mechanisms regulate the mammalian circadian clock. Cell 107: 855-867.

Lee, K., Dunlap, J.C., and Loros, J.J. 2003. Roles for WHITE COLLAR-1 in Circadian and General Photoperception in Neurospora crassa. Genetics 163: 103-114.

Leipe, D.D., Aravind, L., Grishin, N.V., and Koonin, E.V. 2000. The bacterial replicative helicase DnaB evolved from a RecA duplication. Genome Res. 10: 5-16.

Lewis, Z.A., Correa, A., Schwerdtfeger, C., Link, K.L., Xie, X., Gomer, R.H., Ebbole, D.J., and Bell-Pedersen, D. 2002. Overexpression of White Collar-1 (WC-1) activates circadian 
clock-associated genes, but is not sufficient to induce most light-regulated gene expression in Neurospora crassa. Mol. Microbiol. 45: 917-931.

Linden, H. and Macino, G. 1997. White collar-2, a partner in blue-light signal transduction, controlling expression of light-regulated genes in Neurospora crassa. EMBO J. 16: 98109.

Linden, H., Rodriguez-Franco, M., and Macino, G. 1997. Mutants of Neurospora defective in regulation of blue light perception. Mol. Gen. Genet. 254: 111-118.

Liu, Y., Garceau, N., Loros, J.J., and Dunlap, J.C. 1997. Thermally regulated translational control of FRQ mediates aspects of temperature responses in the Neurospora circadian clock. Cell 89: 477-486.

Liu, Y., Merrow, M., Loros, J.J., and Dunlap, J.C. 1998. How temperature changes reset a circadian oscillator. Science 281: 825-829.

Liu, Y., Loros, J.J., and Dunlap, J. 2000. Phosphorylation of the Neurospora clock protein FREQUENCY determines its degradation rate and strongly influences the period length of the circadian clock. Proc. Natl. Acad. Sci. 97: 234-239.

Liu, Y., He, Q., and Cheng, P. 2003. Photoreception in Neurospora: A tale of two White Collar proteins. Cell. Mol. Life Sci. 60: 2131-2138.

Loros, J. 2005. A kinase for light and time. Mol. Microbiol. 56: 299-302.

Lowrey, P.L., Shimomura, K., Antoch, M.P., Yamazaki, S., Zmenides, P.D., Ralph, M.R., Menaker, M., and Takahashi, J.S. 2000. Positional syntenic cloning and functional characterization of the mammalian circadian mutation tau. Science 288: 483-492.

Luo, C., Loros, J.J., and Dunlap, J.C. 1998. Nuclear localization is required for function of the essential clock protein FRQ. EMBO J. 17: 1228-1235.

Marchal, C., Haguenauer-Tsapis, R., and Urban-Grimal, D. 1998. A PEST-like sequence mediates phosphorylation and efficient ubiquitination of yeast uracil permease. Mol. Cell. Biol. 18: 314-321.

McDonald, M.J. and Rosbash, M. 2001. Microarray analysis and organization of circadian gene expression in Drosophila. Cell 107: $567-578$.

Merrow, M.W. and Dunlap, J.C. 1994. Intergeneric complementation of a circadian rhythmicity defect: Phylogenetic conservation of structure and function of the clock gene frequency. ЕMBO J. 13: 2257-2266.

Merrow, M.W., Garceau, N., and Dunlap, J. 1997. Dissection of a circadian oscillation into discrete domains. Proc. Natl. Acad. Sci. 94: 3877-3882.

Merrow, M.W., Brunner, M., and Roenneberg, T. 1999. Assignment of circadian function for the Neurospora clock gene frequency. Nature 399: 584-586.

Merrow, M., Franchi, L., Dragovic, Z., Görl, M., Johnson, J., Brunner, M., Macino, G., and Roenneberg, T. 2001. Circadian regulation of the light input pathway in Neurospora crassa. EMBO I. 20: 307-315.

Mitchell, P. and Tollervey, D. 2000. Musing on the structural organization of the exosome complex. Nat. Struct. Biol. 7: 843-846.

Mori, T. and Johnson, C.H. 2001. Circadian programming in cyanobacteria. Semin. Cell Dev. Biol. 12: 271-278.

Mori, T., Saveliev, S.V., Xu, Y., Stafford, W.F., Cox, M.M., Inman, R.B., and Johnson, C.H. 2002. Circadian clock protein KaiC forms ATP-dependent hexameric rings and binds DNA. Proc. Natl. Acad. Sci. 99: 17203-17208.

Nakahira, Y., Katayama, M., Miyashita, H., Kutsuna, S., Iwasaki, H., Oyama, T., and Kondo, T. 2004. Global gene repression by KaiC as a master process of prokaryotic circadian system. Proc. Natl. Acad. Sci. 101: 881-885.

Nakajima, M., Imai, K., Ito, H., Hishiwaki, T., Murayama, Y., Iwasaki, H., Qyama, T., and Kondo, T. 2005. Reconstitution of circadian oscillation of cyanobacterial KaiC phosphorylation in vitro. Science 308: 414-415.

Nawathean, P. and Rosbash, M. 2004. The Doubletime and CKII kinases collaborate to potentiate Drosophila PER transcriptional repressor activity. Mol. Cell 13: 213-223.

Nishiwaki, T., Iwasaki, H., Ishiura, M., and Kondo, T. 2000. Nucleotide binding and autophosphorylation of the clock protein KaiC as a circadian timing process of cyanobacteria. Proc. Natl. Acad. Sci. 97: 495-499.

Nishiwaki, T., Satomi, Y., Nakajima, M., Lee, C., Kiyohara, R., Kageyama, H., Kitayama, Y., Temamoto, M., Yamaguchi, A., Hijikata, A., et al. 2004. Role of KaiC phosphorylation in the circadian clock system of Synechococcus elongatus PCC 7942. Proc. Nat1. Acad. Sci. 101: 13927-13932.

Nowrousian, M., Duffield, G.E., Loros, J.J., and Dunlap, J.C. 2003. The frequency gene is required for temperature-dependent regulation of many clock-controlled genes in Neurospora crassa. Genetics 164: 923-933.

Oishi, K., Miyazaki, K., Kadota, K., Kikuno, R., Nagase, T., Atsumi, G., Ohkura, N., Azama, T., Mesaki, M., Yukimasa, S., et al. 2003. Genome-wide expression analysis of mouse liver reveals CLOCK-regulated circadian output genes. J. Biol. Chem. 278: 41519-41527.

Pregueiro, A.M., Price-Lloyd, N., Bell-Pedersen, D., Heintzen, C., Loros, J.J., and Dunlap, J.C. 2005. Assignment of an essential role for the Neurospora frequency gene in circadian entrainment to temperature cycles. Proc. Natl. Acad. Sci. 102: $2210-2215$

Preitner, N., Damiola, F., Lopez-Molina, L., Zakany, J., Duboule, D., Albrecht, U., and Schibler, U. 2002. The orphan nuclear receptor REV-ERB $\alpha$ controls circadian transcription within the positive limb of the mammalian circadian oscillator. Cell 110: 251-260.

Price, J.L., Blau, J., Rothenfluh, A., Abodeely, M., Kloss, B., and Young, M.W. 1998. Double-time is a novel Drosophila clock gene that regulates PERIOD protein accumulation. Cell 94: 83-95.

Rechsteiner, M. and Rogers, S.W. 1996. PEST sequences and regulation by proteolysis. Trends Biochem. Sci. 7: 267-271.

Ripperger, J.A. and Schibler, U. 2006. Rhythmic CLOCK/ BMAL1 binding to multiple E-box motifs drives circadian Dbp transcription and chromatin transitions. Nat. Genet. 38: $369-374$.

Roenneberg, T. and Merrow, M. 2003. The network of time: Understanding the molecular circadian system. Curr. Biol. 13: R198-R207.

Roenneberg, T., Dragovic, Z., and Merrow, M. 2005. Demasking biological oscillators: Properties and principles of entrainment exemplified by the Neurospora circadian clock. Proc. Natl. Acad. Sci. 102: 7742-7747.

Rogers, S., Wells, R., and Rechsteiner, M. 1986. Amino acid sequences common to rapidly degraded proteins: The PEST hypothesis. Science 234: 364-368.

Roth, A.F. and Davis, N.G. 2000. Ubiquitination of the PESTlike endocytosis signal of the yeast a-factor Receptor. J. Biol. Chem. 275: 8143-8153.

Salome, P.A. and McClung, C.R. 2004. The Arabidopsis circadian clock. J. Biol. Rhythms 19: 425-435.

Sathyanarayanan, S., Zheng, X., Xiao, R., and Seghal, A. 2004. Posttranslational regulation of Drosophila PERIOD protein by protein phosphatase 2A. Cell 116: 603-615.

Sato, T.K., Panda, S., Miraglia, L.J., Reyes, T.M., Rudic, R.D., 
McNamara, P., Naik, K.A., FitzGerald, G.A., Kay, S.A., and Hogenesch, J.B. 2004. A functional genomics strategy reveals Rora as a component of the mammalian circadian clock. Neuron 43: 527-537.

Sato, T.K., Yamada, R.G., Ukai, H., Baggs, J.E., Miraglia, L.J., Kobayashi, T.J., Welsh, D.K., Kay, S.A., Ueda, H.R., and Hogenesch, J.B. 2006. Feedback repression is required for mammalian circadian clock function. Nat. Genet. 38: 312-319.

Schafmeier, T., Haase, A., Káldi, K., Scholz, J., Fuchs, M., and Brunner, M. 2005. Transcriptional feedback of Neurospora circadian clock gene by phosphorylation-dependent inactivation of its transcription factor. Cell 122: 235-246.

Schafmeier, T., Káldi, K., Diernfellner, A., Mohr, C., and Brunner, M. 2006. Phosphorylation-dependent maturation of Neurospora circadian clock protein from a nuclear repressor toward a cytoplasmic activator. Genes \& Dev. 20: 297-306.

Schmidthauser, T.J., Lauter, F.R., Russo, V.E., and Yanofsky, C. 1990. Cloning, sequence and photoregulation of al-1, a carotenoid biosynthetic gene of Neurospora crassa. Mol. Cell. Biol. 10: 5064-5070.

Schmidthauser, T.J., Lauter, F.R., Schumacher, M., Zhou, W., Russo, V.E., and Yanofsky, C. 1994. Characterization of al-2, the phyotene synthase gene of Neurospora crassa. Cloning, sequence and photoregulation. J. Biol. Chem. 269: 1206012066.

Schwerdtfeger, C. and Linden, H. 2000. Localization and lightdependent phosphorylation of white collar 1 and 2, the two central components of blue light signaling in Neurospora crassa. Eur. J. Biochem. 267: 414-422.

- 2001. Blue light adaptation and desensitization of light signal transduction in Neurospora crassa. Mol. Microbiol. 39: $1080-1087$.

- 2003. VIVID is a flavoprotein and serves as a fungal blue light receptor for photoadaptation. EMBO J. 22: 4846-4855.

Shearman, L.P., Sriram, S., Weaver, D.R., Maywood, E.S., Chaves, I., Zheng, B., Kume, K., Lee, C.C., van der Horst, G.T., Hastings, M.H., et al. 2000. Interacting molecular loops in the mammalian circadian clock. Science 288: 10131019.

Shrode, L.B., Lewis, Z.A., White, L.D., Bell-Pedersen, D., and Ebbole, D.J. 2001. vvd is required for light adaptation of conidiation-specific genes of Neurospora crassa, but not circadian conidiation. Fungal Genet. Biol. 32: 169-181.

Stanewsky, R. 2003. Genetic analysis of the circadian system in Drosophila melanogaster and mammals. J. Neurobiol. 54: 111-147.

Talora, C., Franchi, L., Linden, H., Ballario, P., and Macino, G. 1999. Role of a white collar-1-white collar-2 complex in blue-light signal transduction. EMBO J. 18: 4961-4968.

Tan, Y., Dragovic, Z., Roenneberg, T., and Merrow, M. 2004. Entrainment dissociates transcription and translation of a circadian clock gene in Neurospora. Curr. Biol. 14: 433-438.

Tomita, J., Nakajima, M., Kondo, T., and Iwasaki, H. 2005. No transcription-translation feedback in circadian rhythm of KaiC phosphorylation. Science 307: 251-254.

Torchet, C., Bousquet-Antonelli, C., Milligan, L., Thompson, E., Kufel, J., and Tollervey, D. 2002. Processing of 3 '-extended read-through transcripts by the exosome can generate functional mRNAs. Mol. Cell 9: 1285-1296.

Ueda, H.R., Chen, W., Adachi, A., Wakamatsu, H., Hayashi, S., Takasugi, T., Nagano, M., Nakahama, K., Suzuki, Y., Sugano, S., et al. 2002. A transcription factor response element for gene expression during circadian night. Nature 418: 534539.

Vielhaber, E.L., Eide, E., Rivers, A., Zhong-Hua, G., and Virshup, D.M. 2000. Nuclear entry of the circadian regulator
mPER 1 is controlled by mammalian casein kinase $1 \varepsilon$. Mol Cell. Biol. 20: 4888-4899.

Virshup, D.M. 2000. Protein phosphatase 2A: A panoply of enzymes. Curr. Opin. Cell Biol. 12: 180-185.

Xu, Y., Mori, T., and Johnson, C.H. 2000. Circadian clock-protein expression in cyanobacteria: Rhythms and phase setting. EMBO J. 19: 3349-3357.

. 2003. Cyanobacterial circadian clockwork: Roles of KaiA, KaiB and the kaiBC promoter in regulating KaiC. EMBO J. 22: 2117-2126.

Xu, Y., Mori, T., Pattanayek, R., Pattayanek, S., Egli, M., and Johnson, C.H. 2004. Identification of key phosphorylation sites in the circadian clock protein KaiC by crystallographic and mutagenetic analyses. Proc. Nat1. Acad. Sci. 101: 1393313938.

Yang, Y., Cheng, P., Zhi, G., and Liu, Y. 2001. Identification of a calcium/calmodulin-dependent protein kinase that phosphorylates the Neurospora circadian clock protein FREQUENCY. J. Biol. Chem. 276: 41064-41072.

Yang, Y., Cheng, P., and Liu, Y. 2002. Regulation of the Neurospora circadian clock by casein kinase II. Genes \& Dev. 16: 994-1006.

Yang, Y., Cheng, P., He, Q., Wang, L., and Liu, Y. 2003. Phosphorylation of FREQUENCY protein by casein kinase II is necessary for the function of the Neurospora circadian clock. Mol. Cell. Biol. 23: 6221-6228.

Yang, Y., He, Q., Cheng, P., Wrage, P., Yarden, O., and Liu, Y. 2004. Distinct roles for PP1 and PP2A in the Neurospora circadian clock. Genes \& Dev. 18: 255-260. 


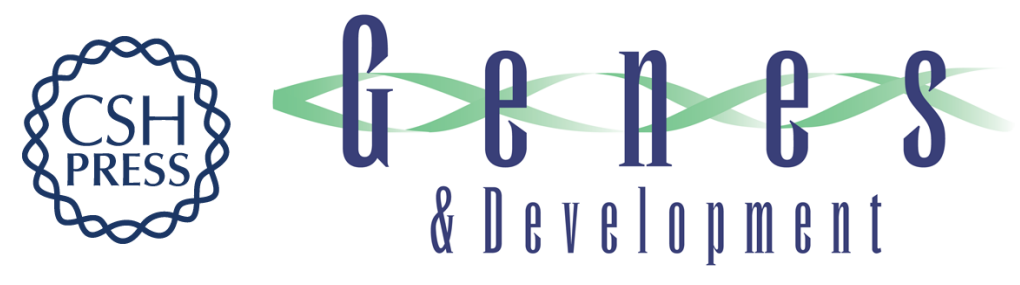

\section{Transcriptional and post-transcriptional regulation of the circadian clock of cyanobacteria and Neurospora}

Michael Brunner and Tobias Schafmeier

Genes Dev. 2006, 20:

Access the most recent version at doi:10.1101/gad.1410406

$\begin{array}{ll}\text { References } & \begin{array}{l}\text { This article cites } 124 \text { articles, } 50 \text { of which can be accessed free at: } \\ \text { http://genesdev.cshlp.org/content/20/9/1061.full.html\#ref-list-1 }\end{array}\end{array}$

License

Email Alerting Receive free email alerts when new articles cite this article - sign up in the box at the top Service right corner of the article or click here.

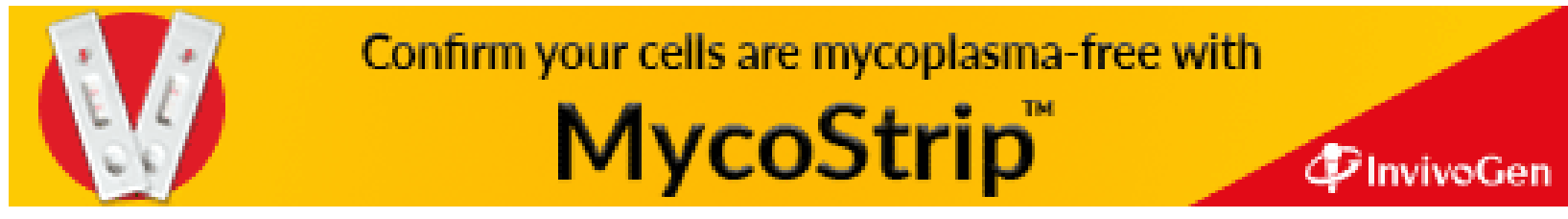

